\title{
Mucin-Type O-Glycans: Barrier, Microbiota, and Immune Anchors in Inflammatory Bowel Disease
}

\author{
Yaqin Zhang ${ }^{1, *}$ \\ Lan Wang ${ }^{2, *}$ \\ Dickson Kofi Wiredu \\ Ocansey $(\mathbb{D})^{1,3}$ \\ Bo Wang' \\ Li Wang ${ }^{4}$
}

Zhiwei Xu'

'Key Laboratory of Medical Science and Laboratory Medicine of Jiangsu Province, School of Medicine, Jiangsu University,

Zhenjiang, Jiangsu, 2I20I3, People's

Republic of China; ${ }^{2}$ Danyang Blood

Station, Zhenjiang, Jiangsu, 212300,

People's Republic of China; ${ }^{3}$ Directorate of University Health Services, University of Cape Coast, PMB, Cape Coast, Ghana;

${ }^{4}$ Huai'an Maternity and Children

Hospital, Huaian, Jiangsu, 223002.

People's Republic of China

*These authors contributed equally to this work
Correspondence: Li Wang

Huai'an Maternity and Children Hospital, 104 Renmin Road, Huaian, Jiangsu,

223200, People's Republic of China

Tel +86 I35 I5230755

Email hafybjy@l63.com

Zhiwei Xu

School of Medicine, Jiangsu University,

30I Xuefu Road, Zhenjiang, Jiangsu,

212013, People's Republic of China

$\mathrm{Tel} / \mathrm{Fax}+8651185038215$

Email zhiweixu@ujs.edu.cn

\begin{abstract}
Inflammatory bowel disease (IBD), which affects about 7 million people globally, is a chronic inflammatory condition of the gastrointestinal tract caused by gut microbiota alterations, immune dysregulation, and genetic and environmental factors. The association of microbial and immune molecules with mucin-type O-glycans has been increasingly noticed by researchers. Mucin is the main component of mucus, which forms a protective barrier between the microbiota and immune cells in the colon. Mucin-type O-glycans alter the diversity of gastrointestinal microorganisms, which in turn increases the level of O-glycosylation of host intestinal proteins via the utilization of glycans. Additionally, alterations in mucin-type O-glycans not only increase the activity and stability of immune cells but are also involved in the maintenance of intestinal mucosal immune tolerance. Although there is accumulating evidence indicating that mucin-type O-glycans play an important role in IBD, there is limited literature that integrates available data to present a complete picture of exactly how O-glycans affect IBD. This review emphasizes the roles of the mucin-type O-glycans in IBD. This seeks to provide a better understanding and encourages future studies on IBD glycosylation and the design of novel glycan-inspired therapies for IBD.
\end{abstract}

Keywords: glycans, inflammation, intestinal mucus, MUC2, microbiota, immunity

\section{Introduction}

IBD is a complex chronic inflammation of the gut, including Crohn's disease (CD) and ulcerative colitis (UC). In recent years, IBD has become a crucial yet difficult field of study among digestive diseases because of high incidence, difficulty of complete remission, and high risk of developing cancer in patients with a long history of the disease. ${ }^{1}$ The etiological factor and pathogenesis of IBD are still unclear. However, its progression is associated with altered interactions between gut microbes and the intestinal immune system, ${ }^{2,3}$ where these factors result in an uncontrolled inflammatory response that ultimately culminates in irreversible tissue damage.

The body can protect itself from the threat of harmful microorganisms, autoimmune disorders, and intestinal inflammation through a variety of mechanisms. An important factor in these mechanisms is the mucus layer covering the intestinal epithelium, which not only provides lubrication for food passage but also protects the epithelial cells beneath it from microorganisms, and establishing a physical barrier against invasion of pathogens, toxins, and other environmental irritants. ${ }^{4-6}$ Defects in the structure of the mucus layer before disease progression have been reported in mouse models of IBD. $^{7}$ Kirk et al redefined the colonic mucus system as 
a biological system composed of a loosely "niche" layer, which provides symbiotic bacterial growth, and the tightly "inner" layer, which acts as a barrier between bacteria and intestinal epithelium. ${ }^{8}$ Johansson et al found that the mucus layer of dextran sulfate sodium(DSS)-induced colitis mice allowed bacteria to pass through. ${ }^{9}$ In IL-10 ${ }^{-/-}$ mice, a widely used mouse colitis model, it has been found that bacteria could pass through the mucus layer without reducing its thickness. ${ }^{10}$ These observations suggest that variation in the "inner" layer may be an initial event in the development of colitis.

The difference in the structure of the two mucus layers mainly lies in mucin, which is produced by surface goblet cells and is released steadily without any stimulation. ${ }^{11}$ Mucins maintain a certain amount, mainly due to the special glycosylated-connectives on the surface, ${ }^{12}$ because the gut itself does not produce any enzymes that can break these connections. ${ }^{13}$ These specific glycosylated links are mucin-types O-glycans, which account for up to $80 \%$ of the mass of the mucin molecules. O-glycans in the "niche" layer are loosely arranged, providing potential binding sites to support the growth of symbiotic and pathogenic bacteria (Figure 1A). ${ }^{14,15}$ In addition, bacteria with mucolytic activity can release monosaccharides from mucinO-glycans and metabolize them, thereby using O-glycans as a source of carbon and energy. The "inner" layer generated by the nets formed by O-glycans staggered on top of one another that adheres firmly to the cell and does not allow bacteria to penetrate keeps the commensal bacteria at bay, but when this first line of defense fails, bacteria come in contact with the epithelium. ${ }^{16,17}$ This event is likely the first in the inflammatory disease UC. ${ }^{10,18}$

\section{O-Glycans as the First Line of Defense in the Colon}

O-glycans of the gastrointestinal tract are the first line of defense against external stimuli. Since O-glycans have been linked to the development of inflammatory colitis, there is the need to pay closer attention to this knowledge in the light of further research exploration. Here, we discuss the functions of the O-glycans in IBD by focusing on the structure of O-glycans, as well as the synthesis of Mucin-type O-glycans.

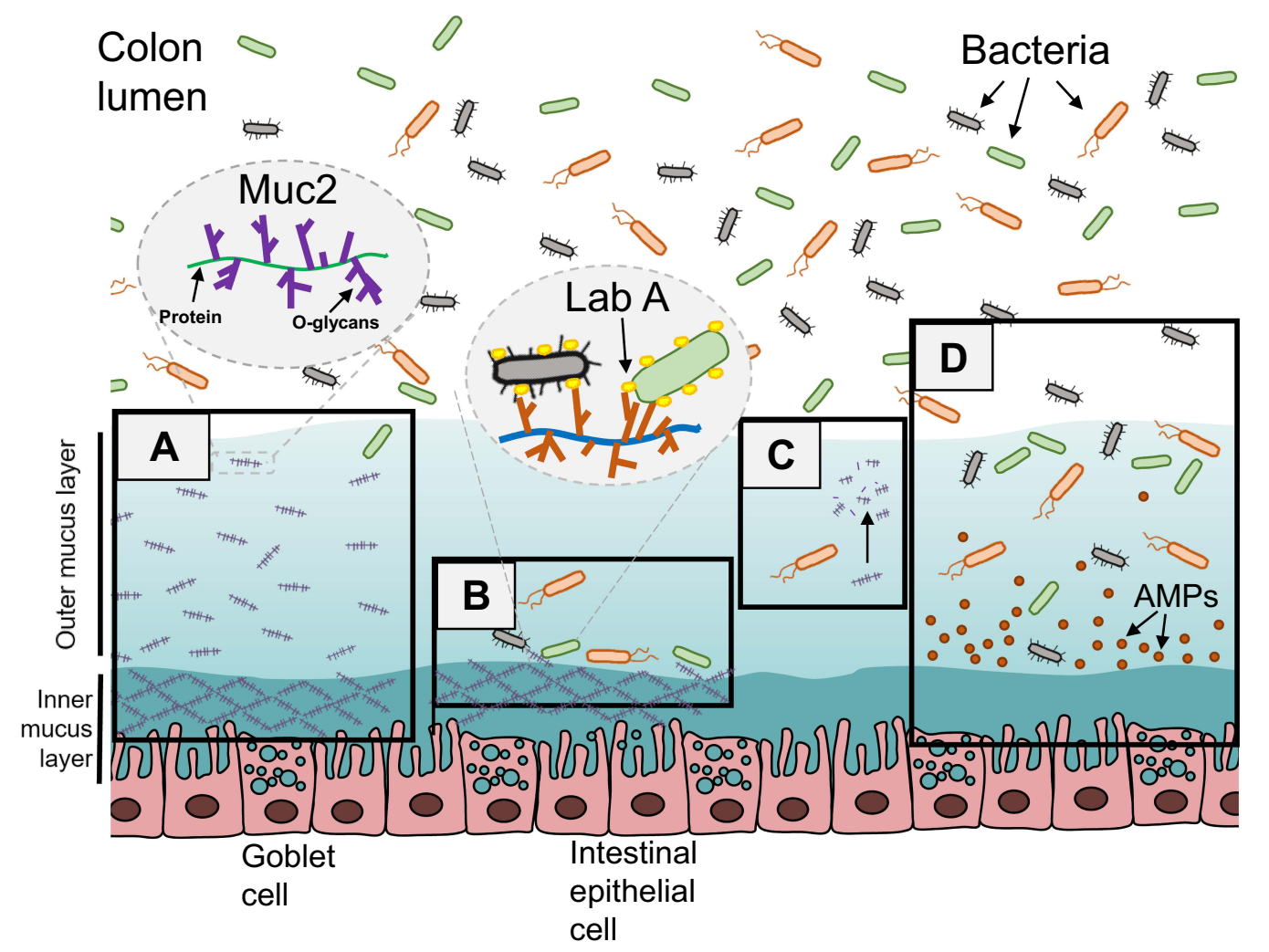

Figure I Interactions between mucin-type O-glycans and intestinal flora. (A) The glycan distribution of the outer mucus is loose, and the glycan of the inner mucus interweaves into a network to act as the mucous membrane barrier; (B) LabA interacts with a lacdiNAc structure (GaINAc $\beta$ I-4GIcNAc) present on the mucin MUC5AC in the gastric mucosal layer; (C) Bacteria decompose glycans into oligosaccharides under the action of glycosidase and use it; (D) the antimicrobial peptides (AMPs) in the mucus I are distributed in step concentration and inhibit bacteria pathogens in the mucus. 


\section{Synthesis of Mucin-Type O-Glycans}

The synthesis of mucin-type O-glycans was shown to have significant associations with the glycosylation process, which is the most complex known posttranslational modification of proteins. It has been discovered that the change of intestinal mucus is related to the change of this post-translational modification of mucin rather than the expression of mucus. ${ }^{19}$ Defects in O-glycosylation can lead to impaired mucin expression and mucosal barrier destruction, which in turn leads to microbial activation of inflammasomes such as caspase 1 , interleukin (IL) $1 \beta$, and IL18, then drive inflammation and lead to severe spontaneous bacteriadependent colitis. ${ }^{20,21}$ The glycosylation of proteins in mammals is mainly classified into three types: O-glycosylation, N-glycosylation, and glycosylphosphatidylinositol (GPI) anchors. O-glycosylation is the main form of glycosylation characterized by the ligation of oligosaccharides including mannose, xylose, and $\mathrm{N}$-acetylgalactosamine (GalNAc) with hydroxyl groups of serine or threonine residues of polypeptide chains to form O-linked glycoproteins. ${ }^{22,23}$ O-linked $\mathrm{N}$-acetylgalactosamine (O-GalNAc) glycan is particularly associated with mucosal sites such as the respiratory tract, urogenital tract, and gastrointestinal tract. $^{24,25}$

The first step of mucin-type O-glycosylation is to transfer N-acetylgalactosamine (GalNAc) to the hydroxyl group of Ser or Thr in the peptide sequence under the action of polypeptide GalNAc transferases (ppGalNAcTs), forming the Tn antigen structure, which is the substrate of glycosyltransferase. ${ }^{26} \mathrm{Tn}$ antigen can be extended to produce eight different core structures (Figure 2), and Core 1-4 are the four main core structures. Core 1 structure is formed by adding galactose to the Tn antigen. The addition of an $\mathrm{N}$-acetylglucosamine to the GalNAc of Core 1 structure forms Core 2 structure. Core 3 structure is produced by the addition of an $\mathrm{N}$-acetylglucosamine (GlcNAc) to the Tn antigen. Core 3 structure can be extended by the addition of a branching GlcNAc at the C6 hydroxyl group of GalNAc to form core 4 structure. Core 1 and 3 structures eventually form most mucin-type O-glycans. ${ }^{27}$ The enzymes involved in core 1-derived O-glycans biosynthesis is core $1 \beta 1,3$-galactosyltransferase $(\mathrm{C} 1 \mathrm{GalT} 1$, or T-synthase), and loss of C1GalT1 efficiently removes all core 1-derived O-glycans in intestinal epithelial cells. Mice with intestinal epithelial-specific defects of core 1-derived
O-glycans show destruction of the inner mucus layer and develop spontaneous colitis, mainly in the distal colon. ${ }^{28}$ These data indicate that the abnormal synthesis of mucosal O-glycan plays an important role in the pathogenesis of colitis, suggesting that it may be possible to treat inflammatory enteritis by repairing glycosylated synthesis.

\section{Mucin-Type O-Glycans Disruption and IBD}

Most structural investigations on O-glycans have been carried out on mucin-type O-glycans, which have been shown to have a great impact on human health and disease, particularly in IBD. To date, 21 different mucins have been identified, many of which are expressed in the gastrointestinal tract and can be broadly classified into three categories: secretory gel-forming (MUC2, MUC5AC, MUC5B, MUC6), secretory non-gel-forming (MUC7), and membrane-bound (eg, MUC1, MUC3, MUC4, MUC12, MUC13, MUC17). ${ }^{26,29-31}$ Studies have shown different patterns of O-glycosylation profile of MUC2 mucins in patients with UC and controls. Patients with active colitis have a decrease in several complex glycans and an increase in a subset of the smaller glycans. Remarkably, patients with strong alterations in the glycans pattern tended to have a more severe disease course. ${ }^{29,32-35}$ strikingly, MUC2 O-glycosylation distribution returns to normal after remission, demonstrating the potential of glycosylation profiling for predicting disease progression, ${ }^{21}$ Studies found that the loss of core 1-derived O-glycans seriously impairs the formation of the mucus layer, leading to severe spontaneous colitis in mice after 2 weeks of birth, and with time, the severity of the disease is gradually aggravated. ${ }^{28,35,36}$ Importantly, mucus depletion was observed before the onset of colitis in mice, supporting the etiological role of core 1-derived O-glycosylation deficiency and mucus barrier function in the pathogenesis of IBD.

A similar deficiency in mucus layer function has recently been found in human UC tissues. ${ }^{9}$ Interestingly, the loss of core 3-derived O-glycans resulted in increased intestinal mucosal permeability, elevated bacterial levels in the colon, and susceptibility to IBD, but no spontaneous disease was observed in $\mathrm{C} 3 \mathrm{GnT}$ knockout mice. ${ }^{37}$ Like C1GalT1, C3GnT is the only enzyme catalyzing the biosynthesis of core 3-derived $\mathrm{O}$ glycan in humans. ${ }^{37}$ Different from humans, the core 3-derived glycans account for only $1 \%$ of the total amount of MUC2 


\section{Glycoprotein}

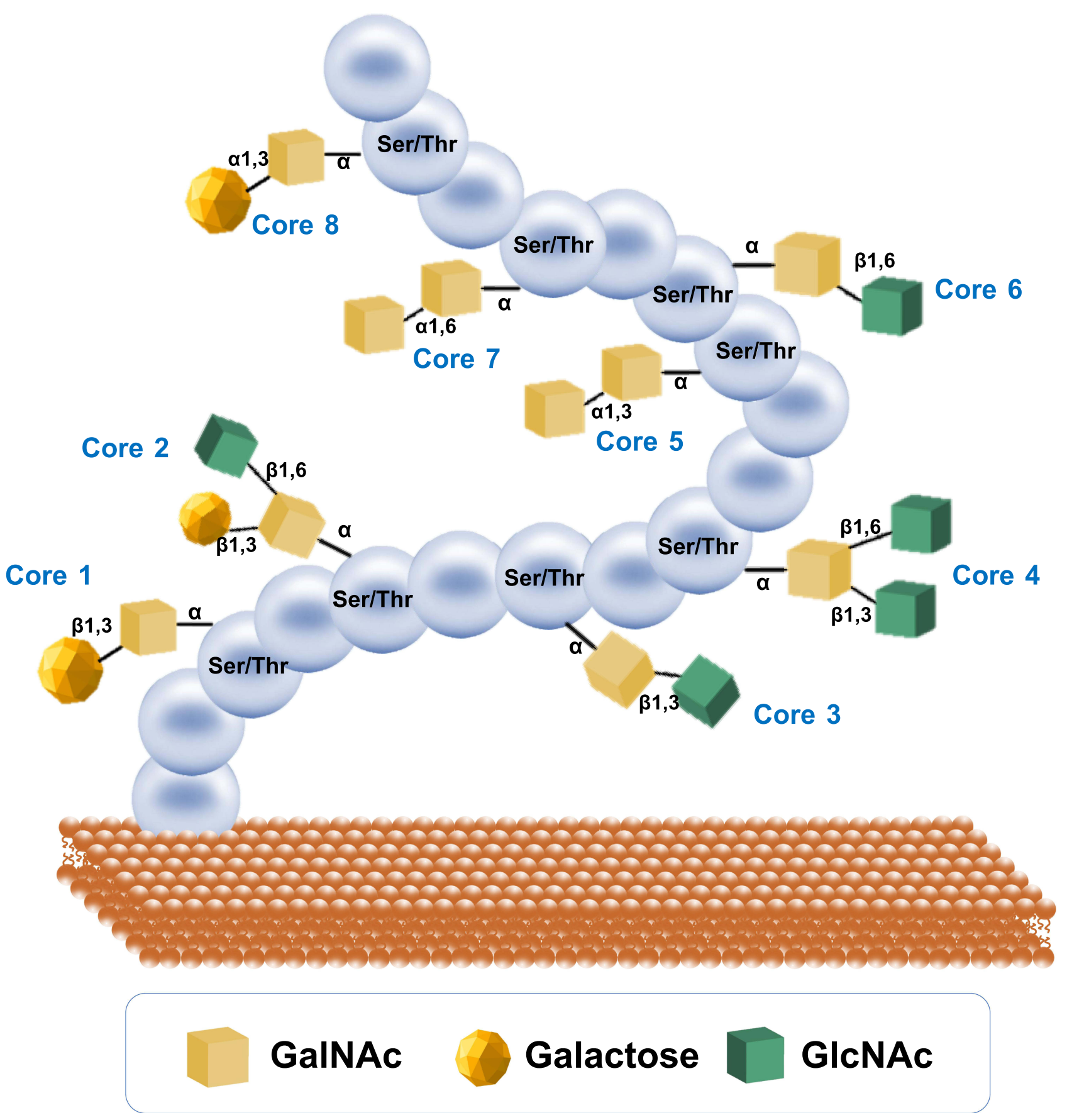

Figure 2 O-glycans structure core I-8. Core I and core 2 structures are the most abundant out of the eight identified mammalians core structures. Core I structure is composed of galactose and is attached to the base GalNAc. Core 2 structure utilizes the core I structure complex with an addition of GlcNAc. Core 3 structure is produced by the addition of a GlcNAc to the TN antigen. Core 3 structure can be extended by the addition of a branching GlcNAc at the C6 hydroxyl group of GalNAc to form core 4 structure.

Abbreviations: GalNAc, N-acetylgalactosamine; GlcNAc, N-acetylglucosamine.

O-glycans in mice, ${ }^{38}$ which may explain why the mice did not develop the spontaneous disease in the absence or loss of core 3 -derived O-glycans. ${ }^{21}$ Core 1 and 3 derived
O-glycans in mucus have the same function, that is, to protect the gut from microbes and thus suppress inflammation. 
Based on current studies, it is known that mucin-type O-glycans are the main factor that plays a protective role in the mucosal barrier; however, there are still many unanswered questions about how O-glycans interact with bacteria specifically to promote the integrity of the mucus barrier and intestinal flora homeostasis.

\section{Interactions Between Mucin-Type O-Glycans and Microorganisms}

Compared with healthy individuals, IBD patients have an unstable microbiota and develop significant bacterial malnutrition. In other words, patients with IBD have fewer anti-inflammatory bacteria and more bacteria with proinflammatory properties. ${ }^{39}$ Remarkably, dysregulation of the microbiota is critical for IBD, because the intestinal habitat of the host can shape microbial community structure. In a study by John Rawls, the performance of reciprocal microbiota transplantations in germ-free zebrafish and mice resulted in a different microbial community structure between the zebrafish and mice due to different selective pressures applied within the gut habitat of each host. ${ }^{40}$ Moreover, the differences between mice and human commensal bacteria support the idea that hosts can influence their bacteria population and diversity. ${ }^{41,42}$ Host factors significantly influence the selection of microbes in the gut. Therefore, the question that remains to be explored is how the host "dictates" the microbe's population and diversity in the gut.

The mechanism that influences or participates in selecting the host's bacteria remains unknown but might involve mucin-type O-glycans. Mucin, especially intestinal mucin MUC2 O-glycans, is probably helpful in selecting colonic flora of a particular species. ${ }^{36}$ Additionally, specific structures on mucin-type O-glycans that bind to bacterial agglutinin-like adhesins probably also influence the composition of intestinal colonies. ${ }^{43,44}$

\section{Mucin-Type O-Glycans Regulate Microbial Composition}

Intestinal flora disturbance can break the ecological balance between normal cells of the small intestine and various microorganisms, including probiotics and pathogenic bacteria, and is one of the leading causes of IBD. Microorganism species also change in mice with O-glycan modification, as shown in mice with Core-1 glycan deficiency in the small intestine. ${ }^{45}$ These mice have higher levels of Bacteroidetes and lower levels of
Firmicutes than wild-type mice. This suggests that O-glycans have become increasingly important in shaping the composition of the microbial community in the gut. This has been demonstrated in mice lacking $\beta 1$, 4-N-acetylgalactosamine transferase 2 (B4galnt2), which catalyzes GalNAc formation to SDA ${ }^{-/}$Cad antigen. ${ }^{46}$ Changes in intestinal bacterial community structure of B4galnt2-deficient mice were determined by $16 \mathrm{~S}$ rRNA pyrosequencing. ${ }^{46}$ It is reasonable to speculate that O-glycans may shape intestinal microbiota by forming other structures that "control" intestinal microbiota through glycosyltransferases. It is noteworthy that, glycandeficient mice exhibit loss of colonic mucosa-associated commensal microorganisms without affecting the composition of microbial communities in the small intestine, resulting in spontaneous colitis. ${ }^{47}$

O-glycans in mucus may affect the ability of Escherichia coli to thrive after they colonize. ${ }^{48}$ Direct antimicrobial activity has been demonstrated in the gastric mucosa. Studies have shown that the barrier layer of the gastric mucosa is mainly composed of MUC6. MUC6 has been shown to carry $\alpha 1-4$ linked $\mathrm{N}$-acetylglucosamine ( $\alpha 1-4$ GlcNAc), with residues attached to core 2 branched O-glycans. ${ }^{49}$ These glycans act as a natural antibiotic by inhibiting the growth of Helicobacter pylori via reducing the formation of cholesterol- $\alpha$-D-glucopyranoside, an essential component of Helicobacter pylori cell wall. ${ }^{50}$ It is plausible that similar antimicrobial O-glycans can exist in the gut. These results suggest that subtle differences in the structure of O-glycans can influence the composition of microbial species, which may influence susceptibility to intestinal diseases.

A growing body of evidence suggests that mucin glycosylation is critical to the biological and physical role in the gut through its regulation of the composition of mucusassociated microbiota. ${ }^{51}$ Interestingly, a recent publication by Bergstrom et al reports that mucus exhibits another functional aspect, showing that proximally derived O-glycosylated mucus encapsulates the fecal and microbiota to regulate the structure and function of the microbiota, as well as transcription in the colonic mucosa. ${ }^{52}$

As the main bearer of intestinal mucus biological function, MUC2 O-glycans may be important for the selection of typical bacterial composition. ${ }^{36}$ To this end, certain questions still linger: Does MUC2 glycan participate in the selection of symbiotic flora? How does the mucus lining of the colon relate to colitis and the human disease ulcerative colitis? All these queries require a more detailed 
molecular exploration to enhance understanding of the structure and processing of MUC2 mucin and its related proteins that make up the colonic mucus layer.

\section{Mucin-Type O-Glycans Promote Bacterial Adhesion}

Pathogenic microorganisms breaking through the intestinal mucus barrier and adhering to the intestinal epithelium is considered to be the first step of pathogenic bacterial infection leading to inflammatory enteritis. Therefore, adhesion is closely related to the biological function of intestinal mucus. It has been shown that $\mathrm{C} 1 \mathrm{GalT} 1$ deficient mice cause the loss of core 1-derived O-glycans to disrupt the attachment site of the intestinal flora and alter the composition of the microbiota. ${ }^{53}$ Mucus serves a dual purpose for the microbiota. On one hand, it can encapsulate the gut microbes, limiting bacterial invasion to the deep intestinal mucosa. On the other hand, the carbohydrate structure of mucins, O-glycans, can also provide an initial site of attachment for bacteria including specific pathogens (Figure 1B). ${ }^{54}$ Studies have shown that MUC1, a glycoprotein found in human breast milk, can be attached to some bacteria, such as Campylobacter and enterotoxigenic Escherichia coli (ETEC), and interferes with the colonization of these pathogens in the gut of infants. ${ }^{55,56}$ Glycans may play a major role in the increased ability of pathogenic bacteria to adhere to the intestine. Lectins that mediate the binding of bacteria to host cells are proteins that not only bind glycans on the cell surface but also bind free carbohydrates. Campylobacter jejuni can bind MUC2 through carbohydrate-lectin. ${ }^{57,58}$ Thus, it can be hypothesized that the binding site of Campylobacter to mucin may be O-glycans. In addition to Campylobacter jejuni, Escherichia coli can also bind MUC2. ${ }^{59}$ Moreover, mucin-type O-glycans have been shown to inhibit EHEC adhesion to epithelial cells. ${ }^{60}$ There are few studies on the specific sites of bacterial-binding mucosa, but some studies have emphasized the importance of O-glycans in bacterial adhesion. The 16S rDNA of colonic bacteria in mice deficient in core 3-derived O-glycans was found to be increased, ${ }^{37}$ suggesting that the bacteria may increase mucosal adhesion and transfer through core 3-derived O-glycans.

Unlike pathogenic bacteria, commensal bacteria adopt a different strategy to adhere to mucus. Adherence of commensal bacteria to the intestinal mucus layer and occupation of the area can reduce the likelihood of adhesion of pathogenic microorganisms. Interestingly, studies have shown that the associated mucins are resistant to adhesion on the cell surface. Sumiyoshi et al used chemical primers benzyl- $\alpha$ GalNAc to disrupt mucin O-glycosylation and observed enhanced adhesion properties on the surface of differentiated corneal epithelial cells. ${ }^{61,62}$ Current studies have shown that symbiotic bacteria mainly promote their adhesion by secreting mucus-binding proteins. ${ }^{15}$ The specific mechanism of mucus-binding proteins is still unclear. It can be speculated that this process may be related to O-glycans.

\section{Mucin-Type O-Glycans Inhibit the Virulence of Bacterial}

Mucus simultaneously hosts trillions of microbes, but these microbes rarely cause infection in healthy mucus, suggesting that there is a mechanism in the mucus layer that regulates virulence. Changes in the glycosylation pattern of mucin in disease can trigger changes in bacterial phenotypes and alter the binding properties of mucin to microorganisms and their protective functions. ${ }^{63}$ In addition to acting as a carbon source, mucin-type O-glycans can affect the expression of different genes involved in pathogenicity. ${ }^{64}$ Recently, a study has shown that mucintype O-glycans attenuate the virulence of Pseudomonas aeruginosa in infection by inhibiting the expression of virulence genes in Pseudomonas aeruginosa. ${ }^{65}$

Similar observations were seen in Campylobacter jejuni, which can also use MUC2 as a signal to regulate the expression of genes associated with motility, adhesion, invasiveness, and toxin formation. ${ }^{66}$ Furthermore, in the gastrointestinal tract, O-glycans downregulate the Hcp secretion island I-encoded type VI secretion system (H1-T6SS), which is associated with Pseudomonas aeruginosa chronic infections. ${ }^{67}$ These studies provide new and exciting insights into the role of mucus and its derived O-glycans as a promising prophylaxis factor against bacterial virulence. Thus, mucintype O-glycans are an effective host signal that can reduce the harm of microorganisms to the host by regulating its toxicity. These studies also demonstrate the potential of mucin-type O-glycan to regulate microbial virulence and provided a theoretical basis for further studies on the prevention of inflammatory enteritis by mucin-type O-glycans.

\section{Bacteria Degrade Glycans as a Source of Nutrients}

The permanent renewal of the mucus layer in the gut represents an important ecological niche that is rich in nutrients and provides a particularly beneficial environment for commensal bacteria. Commensal bacteria are 
typically characterized by abundant glycosylating enzymes, such as glycosidases. When dietary glycans are scarce, bacteria with mucolytic activity can degrade mucin-type O-glycans and metabolize them (Figure 1C), ${ }^{68}$ thus this greatly increases the energy extracted from the food. Moreover, these sugars can also be used by nearby bacteria. ${ }^{15}$ By analyzing the mucintype O-glycans in the feces of patients with UC, researchers found that the ratio of mucin-type O-glycans in the feces of patients with UC was significantly higher than that of healthy people, suggesting that the utilization of O-glycans by intestinal flora in patients with UC was impaired, ${ }^{69}$ Indeed, various anaerobic bacteria species of gut microbiota, such as Akkermansia muciniphila, ${ }^{70,71}$ Bacteroides thetaiotaomicron, ${ }^{72,73}$ Bifidobacterium bifidum, ${ }^{74-76}$ Bacteroides fragilis, ${ }^{77-79}$ Ruminococcus gnavus, ${ }^{74,80}$ and Ruminococcus torquesare now known as mucin-degrading specialists (Table 1). ${ }^{74}$ Bacteroidetes are one of the most abundant symbiotic genera in the human colon. ${ }^{81}$ Bacteroides play an important role in the balance of intestinal flora in inflammatory enteritis, colorectal cancer, and other intestinal diseases. ${ }^{82,83}$ The monosaccharides released during the degradation of mucin-type O-glycans can also serve as chemical cues to help pathogens sense their environment and adapt accordingly.
Bacteria recognize dense mucin O-glycans structures and degrade individual glycan to produce short-chain fatty acids (SCFA), which diffuse through the internal mucus layer and provide an energy source for intestinal epithelial cells. ${ }^{84}$ The harvesting of degraded glycans for their metabolism provides colonization advantages for bacteria. At the same time, this glycan degradation allows oligosaccharides to be provided to non-mucin-degrading bacteria as part of the microbial food chain, thus sustaining the entire intestinal flora. ${ }^{85,86}$

\section{Bacteria Promote O-Glycans Synthesis and Influence Its Composition}

The symbiotic bacteria can affect the composition of goblet cells in the small intestine and their secreted product mucin, thereby increasing the resistance of Intestinal to pathogenic bacteria. Transcriptions of glycosyltransferases involved in core $2 \mathrm{O}$-glycan biosynthesis were observed during experimental mycobacterium tuberculosis infection. $^{87} \mathrm{~A}$ further notice of the regulatory role of glycosyltransferases in bacterial infection highlights the importance of glycans and its biosynthetic pathway as a possible new target for the regulation of IBD. A study has shown that differences in mucin composition are also influenced by the presence or absence of microbial flora in the intestine. ${ }^{88}$ B. thetaiotaomicron metabolizes acetate and enhances goblet cell differentiation, resulting in

Table I Glycan-Degrading Bacteria Colonizing the Human GI Tract

\begin{tabular}{|c|c|c|}
\hline Bacterial Species & Mucin Tested & Enzymatic Activities \\
\hline Akkermansia muciniphila ${ }^{70,71}$ & PPGM type III & $\begin{array}{l}\alpha \text {-Galactosidase; } \beta \text {-galactosidase; } \alpha \text {-L-fucosidase; } \beta \text {-glucosidase; } \alpha \text {-mannosidase; } \alpha \text { - } \\
\text { galactosidase; } \beta \text {-D-fucosidase; } \alpha \text { - } N \text {-acetylgalactosaminidase; } \beta \text { - } \\
\mathrm{N} \text {-acetylgalactosaminidase; } \beta \text { - } \mathrm{N} \text {-acetylglucosaminidase }\end{array}$ \\
\hline $\begin{array}{l}\text { Bacteroides thetaiotaomicron } \\
76\end{array}$ & $\begin{array}{l}\text { Purified O-glycans } \\
\text { from PGM type III }\end{array}$ & $\alpha$-L-fucosidase; endo- $\beta-N$-acetylglucosaminidase; endo- $\beta$-galactosidase; $\alpha$-mannosidase \\
\hline \multirow[t]{2}{*}{ Bifidobacterium bifidum ${ }^{75-77}$} & PGM type III & Endo- $\alpha-\mathrm{N}$-acetylgalactosaminidase; $\alpha \mathrm{I}, 2$-L-fucosidase \\
\hline & PPGM* & $\begin{array}{l}\text { Blood group } \mathrm{H} \text {-degrading activity; sialidase; } \beta \text {-galactosidase; } \beta \text { - } \mathrm{N} \text {-acetylgalactosaminidase; } \\
\beta \text { - } \mathrm{N} \text {-acetylglucosaminidase; sialate } \\
\text { O-acetylesterase; glycosulfatase }\end{array}$ \\
\hline Bacteroides fragilis ${ }^{77-79}$ & PGM type III & endo- $\alpha$ - $\mathrm{N}$-acetylgalactosaminidase; $\alpha \mathrm{I}, 2$-L-fucosidase \\
\hline Ruminococcus gnavus ${ }^{74,80}$ & $\begin{array}{l}\text { PPGM type III } \\
\text { pPGM* }\end{array}$ & $\begin{array}{l}\alpha \text {-L-fucosidase; } \alpha 2,3 \text {-sialidase } \\
\text { Blood group B-degrading activity; blood group } \mathrm{H} \text {-degrading activity; sialidase; } \beta \text { - } \\
\text { galactosidase; sialate } \\
\text { O-acetylesterase }\end{array}$ \\
\hline Ruminococcus torques ${ }^{74}$ & pPGM* & Unknown \\
\hline
\end{tabular}

Abbreviations: PGM, pig gastric mucin; PGM*, pig gastric mucin; pPGM, purified PGM, purified according to Miller and Hoskins' method (Miller and Hoskins, I98I). 
increased goblet cell number and mucin gene expression in rat colon. In addition, mucin glycosylation is substantially changed after colonization by $B$. thetaiotaomicron, that is, the content of $\mathrm{N}$-acetylglucosamine modified glycan decreased. ${ }^{73}$ It can be hypothesized that there is a mechanism by which the bacterium may require low levels of $\mathrm{N}$-acetylglucosamine modified glycosylation to attach and colonize the gut. $F$. prausnitzii consumes the acetate produced by $B$. thetaiotaomicron to produce butyrate. $^{73}$ SCFA, especially butyrate, has an inducer effect on mucin synthesis in vitro. ${ }^{89-91}$ Bacteria not only indirectly affect mucin-type O-glycans by affecting goblet cell secretion and mucin synthesis but can also directly change the diversity and abundance of O-glycans. Gastritis induced by Helicobacter pylori is accompanied by a sharp but transient decrease in the diversity and relative abundance of $\mathrm{O}$-glycans in the mucosa of rhesus monkeys. ${ }^{92}$ Porcine dysenteric spirochete infection can regulate mucin glycosylation and induce increased Core 2-derived O-glycans expression in the porcine colon. In addition, one of the prominent glycosylation changes observed in pigs infected with Pterospira dysenteriae was an increase in the abundance of shorter glycans. ${ }^{93}$ Patients with active UC also show elevated levels of small glycan subsets, which are thought to be associated with inflammation and disease severity. ${ }^{21}$ These results suggest that gut bacteria not only sense the composition of mucus and passively adapt to it but also modify mucintype O-glycans to make the gut more suitable for their own survival.

\section{Mucin-Type O-Glycans and Immune Response}

People with immune deficiency or abnormalities have a higher incidence of IBD and higher levels of intestinal inflammation. ${ }^{94}$ Both the innate and adaptive immune responses play an indispensable role in the immune mechanism of intestinal inflammation caused by O-glycan abnormalities. Intestinal mucus is the first line of defense against pathogens and plays an important role in regulating the homeostasis of microbial flora, clarifying pathogens, and maintaining immune tolerance to foreign food antigens. ${ }^{95,96}$ Mucus is a complex fluid that is rich in mucin glycoproteins, which work together with antimicrobial epithelial AMPs to create a gradient of antimicrobial mucus that prevents bacteria from reaching the epithelial cells (Figure 1D).
The glycans are also inseparable from the host's second line of defense against pathogens, which is the immune cells in the intestinal mucosa that recognize "good" and "bad" bacteria. Mucin-type O-glycans can bind to microorganisms, and the structure and negative charge of glycoproteins are conducive to encapsulating bacteria, thus enhancing host interaction as observed in the early stages of IBD. ${ }^{97,98}$ This indicates that O-glycans can affect the intestinal immune system's recognition of intestinal "nonself" substances. In addition to encapsulating bacteria, mucinous O-glycans also play an important role in the recognition of microorganisms by host immune cells. This is confirmed in a study of MUC1, where an increase in glycosylated MUC1 could lead to continuous activation and accumulation of various cells in the innate immune system, resulting in chronic inflammation. ${ }^{99} \mathrm{M}$ cells in the small intestine, specialized cells that recognize antigens, are characterized by a mucin-free layer and a thin glycocalyx. O-glycans play an indirect role in the interaction between $M$ cells and intestinal antigen by regulating the volume of glycocalyx. ${ }^{100}$ Low glycosylated MUC1 not only provides neoantigen determinants to $\mathrm{B}$ cells but also can be processed and presented to T cells more efficiently. This may promote the movement of adaptive immune cells to the inflammatory site. ${ }^{99}$ In turn, intestinal inflammation also promotes the glycosylation of MUC1 in colonic epithelial cells. ${ }^{101}$ The cause of glycosylation of MUC1 is unknown but may be the result of glycosyltransferase action.

Intestine-related lymphoid tissues directly participate in and regulate intestinal mucosal immune regulation, and are also a predominant part of the body's immune system, including a large number of macrophages, monocytes, natural killer cells (NK cells), dendritic cells (DCs), T cells, and B cells (Table 2). O-glycans of MUC1 sialylTn antigen may affect the immune response by inhibiting the maturation of DCs and the activity of NK cells. ${ }^{102,103}$ Removal of a glycan from the surface of DCs results in increased endocytosis. ${ }^{104}$ Altered genes expression associated with neutrophils, macrophages, mast cells, eosinophils, NK cells, and DCs are observed in Muc2 knockout mice, ${ }^{105}$ suggesting that these immune cells are probably associated with mucin-type O-glycans.

\section{Cells of the Innate Immune System}

Macrophages and monocytes play an important role in the innate immune response to the pathogenesis of IBD. Macrophages have the ability to phagocytosis and digest 
Table 2 Intestinal Immune Cells Associated with O-Glycan

\begin{tabular}{|c|c|c|c|}
\hline Type of Cell & Cell Function & Alter of Glycan & Immune Association \\
\hline$M$ cells $^{99}$ & $\begin{array}{l}\text { Take up antigens from the symbiotic bacteria } \\
\text { to prevent abnormal immune activation } \\
\text { against parasites }\end{array}$ & $\begin{array}{l}\text { A relatively thin } \\
\text { glycocalyx compared } \\
\text { with enterocytes }\end{array}$ & $\begin{array}{l}\text { Glycans promote the contact of } M \text { cells with } \\
\text { antigens }\end{array}$ \\
\hline Macrophages ${ }^{28,107}$ & $\begin{array}{l}\text { Phagocytosis and digestion of "bad" foreign } \\
\text { substances }\end{array}$ & $\begin{array}{l}\text { Core I-derived } \\
\text { O-glycans deficiency } \\
\text { mice }\end{array}$ & $\begin{array}{l}\text { Infiltration of macrophages in the colon tissues; } \\
\text { interfere with the recognition of macrophages to } \\
\text { apoptotic cells }\end{array}$ \\
\hline NK Cells ${ }^{102,100}$ & Neutrophil recruitment & MUC2 deficiency mice & The activity of NK cells \\
\hline$D C s^{106,104}$ & $\begin{array}{l}\text { Presentation of antigens and initiation of } \\
\text { specific immune responses }\end{array}$ & $\begin{array}{l}\text { Cell surface glycan } \\
\text { deficiency }\end{array}$ & $\begin{array}{l}\text { Inhibition of DC maturation; increased } \\
\text { endocytosis }\end{array}$ \\
\hline $\mathrm{T}$ cells $28,109,110$ & $\begin{array}{l}\text { Two subtypes: pro-inflammatory and anti- } \\
\text { inflammatory }\end{array}$ & $\begin{array}{l}\text { Core I-derived } \\
\text { O-glycans maturation } \\
\text { disorder }\end{array}$ & $\begin{array}{l}\text { Pro-inflammatory T cell proliferation; increased } \\
\text { pro-inflammatory factors; }\end{array}$ \\
\hline
\end{tabular}

"bad" foreign substances and express pro-inflammatory (M1-like) or anti-inflammatory (M2-like) phenotypes by sensing the microenvironment. ${ }^{106}$ Patients with $\mathrm{CD}$ have increased numbers of M1 macrophages and monocytes. Other studies have also found increased expression of macrophage-related cytokines in the inflammatory colon tissue. ${ }^{107}$ In the mouse model of colitis, there is an inextricable relationship between macrophages and O-glycans. Studies have shown that the number and function of macrophages and monocytes are altered in colitis in mice with core 1-derived O-glycans deficiency. Significant infiltration of monocytes and macrophages in the colon tissues of core 1-derived O-glycans deficient mice is observed following the onset of colitis. Moreover, there is a significant increase in macrophages in mice with core 1-derived O-glycans deficiency. ${ }^{28}$ This suggests that these cells are the primary cell types capable of sensing early microbial invasion and triggering inflammation. By knocking out core 1 $\beta$-1,3-galactosyltransferase-specific molecular chaperone (Cosmc) in macrophages, which is essential for the synthesis of mucin-type O-glycans. It was found that $\mathrm{O}$-glycans can interfere with the recognition of macrophages' mucin domain-containing molecule 4 to apoptotic cells, thus affecting the phagocytic function of macrophages, leading to incomplete clearance of apoptotic cells by macrophages. ${ }^{108}$

Macrophages can in turn influence mucin glycosylation. For example, O-glycans alterations of MUC1 are driven by $\mathrm{M} 2$ macrophages through overexpression of glycosyltransferase ST6GALNAC1. The modified enzyme added sialic acid to the O-linked GalNAC residues to form the tumor-associated sialic acid Tn O-glycans, and this abnormal glycosylation of MUC1 occurs in chronic inflammation including UC. ${ }^{107}$ Moreover, antigenpresenting cells (APCs), DCs, and macrophages can promote the differentiation of CD4+T cells into helper T(Th)2 cells by phagocytosis and processing antigen, and the cytokine IL-13 secreted by these cells drives intestinal goblet cell proliferation and increases the levels of mucins Muc2 and Muc5a. ${ }^{109,110}$ The close interaction between macrophages and monocytes and mucosal O-glycan suggests that innate immune responses are involved in O-glycan-induced colitis.

\section{Cells of the Adaptive Immune System}

$\mathrm{T}$ cells play a vital role in the pathogenesis of IBD. The imbalance between pro-and anti-inflammatory $\mathrm{T}$ cells may be responsible for the initiation and aggravation of the inflammatory process in patients with IBD. ${ }^{111}$ In patients with active IBD, pro-inflammatory $\mathrm{T}$ cell infiltration is increased in intestinal inflammatory tissues, while antiinflammatory $\mathrm{T}$ regulatory (Treg) cell activity is impaired. ${ }^{111}$ Both $\mathrm{CD}$ and UC are characterized by significant expansion of inflammatory memory $\mathrm{CD} 4+\mathrm{T}$ cells in the inflamed intestine. ${ }^{112,113}$ In the process of intestinal inflammation, Core-2 $\beta 1$, 6-N-acetylglucosamine aminotransferase (C2GNT) 1 is down-regulated, resulting in Core 1-derived O-glycans maturation disorder on the surface of CD4 + T cells. Immature Core 1-derived O-glycans bind to galectin- 4 , a member of the endogenous lectin 
family, which then binds to the glycan structure and controls immune cellular processes, leading to CD4 $+\mathrm{T}$ cell expansion and more severe intestinal inflammation. ${ }^{114}$ Interestingly, another paper found that a reduction in Core-1 O-glycosylation leads to an increase in the Foxp3 + Treg cell, which is microbiota-induced T(regs) cells, that inhibits immune-inflammatory responses. ${ }^{115,116}$ There is a significant increase in microbiota-induced Treg cells (Figure 3) during the disease onset phase (Week 3) of colitis mice specifically deficient in colonic epithelial core 1-derived O-glycans. ${ }^{28,117}$ There is also no significant increase in the number of NK cells in mice with colonic epithelial core 1-derived O-glycans specific deletion. ${ }^{28}$ During the progression of colitis to the relapse stage (Week 9), symptoms in mice with combined deficiency of O-glycans and lymphocytes of core 1 source are milder than those in mice with O-glycans deficiency of core 1 source only, ${ }^{28}$ and pro-inflammatory $\mathrm{T}$ cell subsets proliferate significantly. ${ }^{117}$ This implies that lymphocytes may play an important role in the later stages of colitis.

Although colitis caused by core 1-derived O-glycans deficiency in mice is an inflammatory response driven by innate immunity, not adaptive immunity, ${ }^{28}$ many changes in Th1 and Th2 cells have been observed in glycan knockout mouse enteritis models. Researchers created $\mathrm{C} 3 \mathrm{GnT}$ ${ }^{-/}$mice that lack core 3-derived O-glycans, reduced colon-specific MUC2 protein, and are highly sensitive to colitis. In the absence of DSS, the pro-inflammatory cytokines IL-2, IFN- $\gamma$, and tumor necrosis factor (TNF)- $\alpha$, which are mainly secreted by Th1 cells, are slightly

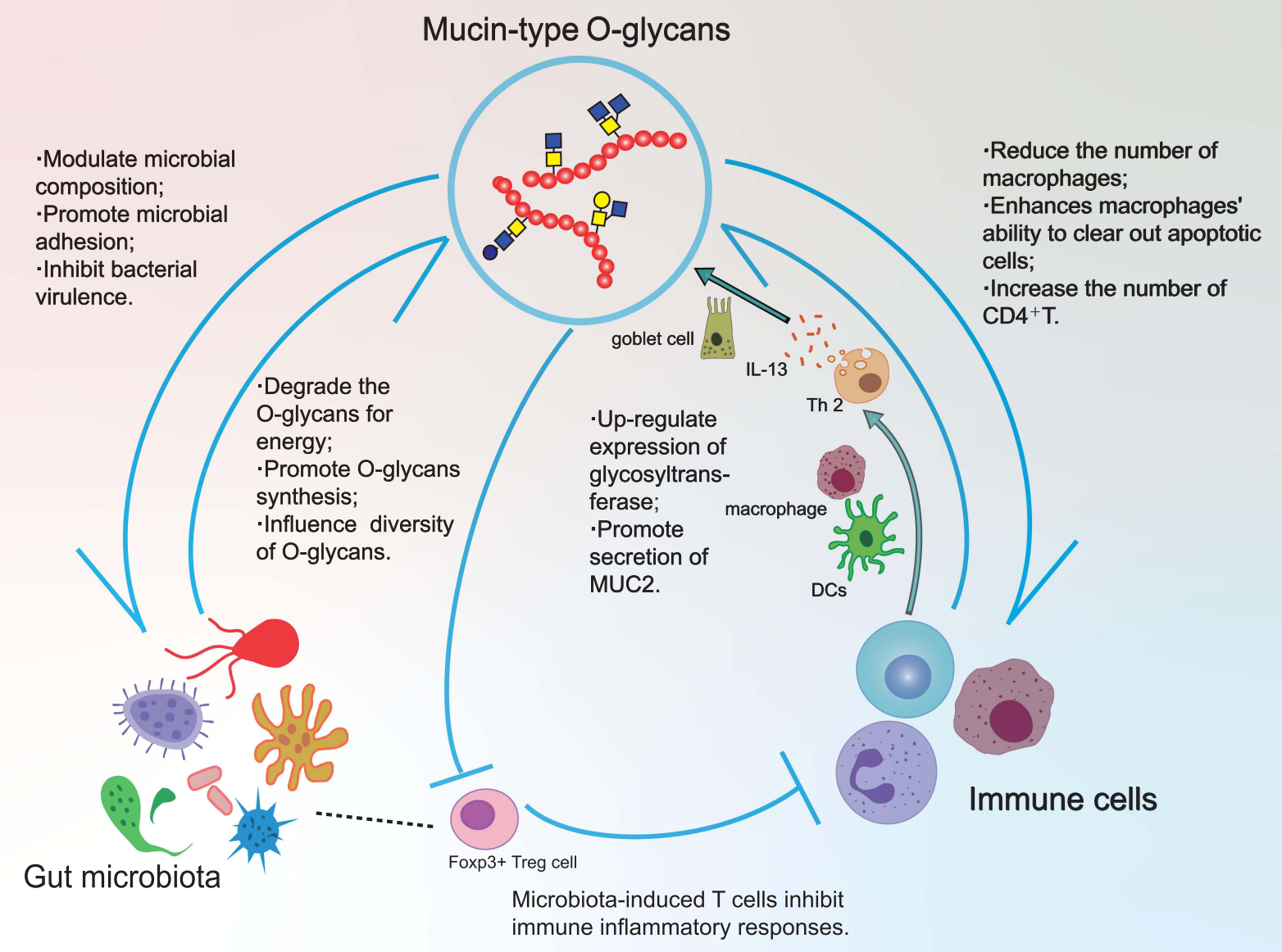

Figure 3 Association between mucin-Type O-glycans, microbiota, and immune cells. O-glycans regulate microbial composition, promote microbial adhesion, and inhibit bacterial virulence. Conversely, intestinal flora can degrade glycan for energy and also affect the composition of glycan. O-Glycans not only affect the number of various immune cells in the body, such as macrophages and $\mathrm{CD} 4^{+} \mathrm{T}$ cells but also enhance the ability of macrophages to remove apoptotic cells. Immune cells mainly secrete inflammatory factors to promote mucin glycosylation. Lack of glycosylation can also affect microbial-related regulatory $\mathrm{T}$ cells, thereby inhibiting immune responses. 
increased in mucosal lymphocytes of $\mathrm{C} 3 \mathrm{GnT}^{-1-}$ mice, but are far from developing into Th17 or Th2 immune colitis. ${ }^{37}$ This suggests that the interaction between O-glycans and lymphocytes is not the main cause of immune colitis. Again, the assertion that the adaptive immune response does not play an important role in the process of colitis caused by O-glycans deficiency is demonstrated.

The glycosylation of the lymphocytes themselves is also associated with colitis. Human glycosyltransferase 1,2-fucosyltransferase (FUT1) transgenic mice are an IBD mouse model with severe glycosylation abnormalities on the lymphocyte surface. A significant reduction in lymphocytes is found in FUT1 transgenic mice, particularly CD4+T cells (reduced by 90\%) and CD8+T cells. In addition to the decrease in the number of $\mathrm{T}$ cells, the nature of $\mathrm{T}$ cells also changes. CD3 is reduced on the surface of $\mathrm{T}$ cells, and a large number of $\mathrm{T}$ cells show both CD4 and CD8 positive markers. ${ }^{118}$ This phenomenon indicates that abnormal glycosylation of lymphocytes can lead to $\mathrm{T}$ lymphocyte depletion and maturation disorders, leading to colitis. In addition, mice with a specific loss of lymphocyte O-glycans had reduced thymus mass, abnormal thymus structure, and bone marrow hypoplasia. ${ }^{118}$ Although current data shows that O-glycan-induced colitis is not adaptive immune-driven, O-glycans is one of the important factors affecting the change of $\mathrm{T}$ cell subsets.

\section{Conclusions}

Several studies have shown that O-glycan is involved in the pathogenesis and development of IBD. Variable O-glycosylation of mucins by large amounts of glycosyltransferases is important for the maintenance of intestinal mucosal barrier function, bacterial-binding capacity, and immune homeostasis. In future research, more attention should be given to the changes in mucosal O-glycan in the mechanism of intestinal flora and immune dysregulation. The intensity of glycosylation changes correlates with the degree of inflammation, suggesting the potential of the glycosylation spectrum to predict IBD progression. In addition, there is the need to develop better experimental animal models that truly reflect human conditions. This means the models should carry human mucins with human glycosylation patterns, which requires some genetic modification in mice. Future explorations should also include the investigation of the association between O-glycan and the microbiota through appropriate, well-designed, and targeted clinical studies.

\section{Acknowledgments}

This research was funded by the National Natural Science Foundation of China (grant no. 32000903), and the Scientific Research Foundation of Jiangsu University for Senior Professional Talents (20JDG48).

\section{Author Contributions}

All authors made substantial contributions to conception and design, acquisition of data, or analysis and interpretation of data; took part in drafting the article or revising it critically for important intellectual content; agreed to submit to the current journal; gave final approval of the version to be published; and agree to be accountable for all aspects of the work.

\section{Disclosure}

The authors declare no conflicts of interest in this work.

\section{References}

1. Francescone R, Hou V, Grivennikov SI. Cytokines, IBD, and colitis-associated cancer. Inflamm Bowel Dis. 2015;21 (2):409-418. doi:10.1097/MIB.0000000000000236

2. Wlodarska M, Kostic AD, Xavier RJ. An integrative view of microbiome-host interactions in inflammatory bowel diseases. Cell Host Microbe. 2015;17(5):577-591. doi:10.1016/j. chom.2015.04.008

3. Imhann F, Vich Vila A, Bonder MJ, et al. Interplay of host genetics and gut microbiota underlying the onset and clinical presentation of inflammatory bowel disease. Gut. 2018;67 (1):108-119. doi:10.1136/gutjnl-2016-312135

4. Paone P, Cani PD. Mucus barrier, mucins and gut microbiota: the expected slimy partners? Gut. 2020;69(12):2232-2243. doi:10.1136/gutjnl-2020-322260

5. Lamont JT. Mucus: the front line of intestinal mucosal defense. Ann N Y Acad Sci. 1992;664:190-201. doi:10.1111/j.17496632.1992.tb39760.x

6. Kim JJ, Khan WI. Goblet cells and mucins: role in innate defense in enteric infections. Pathogens. 2013;2(1):55-70. doi:10.3390/ pathogens 2010055

7. Sun J, Shen X, Li Y, et al. Therapeutic potential to modify the mucus barrier in inflammatory bowel disease. Nutrients. 2016;8 (1):44. doi:10.3390/nu8010044

8. Bergstrom K, Shan X, Casero D, et al. Proximal colon-derived O-glycosylated mucus encapsulates and modulates the microbiota. Science. 2020;370(6515):467-472. doi:10.1126/science. aay 7367

9. Johansson MEV, Gustafsson JK, Sjöberg KE, et al. Bacteria penetrate the inner mucus layer before inflammation in the dextran sulfate colitis model. PLoS One. 2010;5(8):e12238. doi:10.1371/journal.pone. 0012238

10. Johansson MEV, Gustafsson JK, Holmén-Larsson J, et al. Bacteria penetrate the normally impenetrable inner colon mucus layer in both murine colitis models and patients with ulcerative colitis. Gut. 2014;63(2):281-291. doi:10.1136/gutjnl-2012303207 
11. Gum JR, Hicks JW, Gillespie AM, et al. Goblet cell-specific expression mediated by the MUC2 mucin gene promoter in the intestine of transgenic mice. Am J Physiol. 1999;276(3):G666G676.

12. Johansson MEV, Sjövall H, Hansson GC. The gastrointestinal mucus system in health and disease. Nat Rev Gastroenterol Hepatol. 2013;10(6):352-361. doi:10.1038/nrgastro.2013.35

13. Pelaseyed T, Bergström JH, Gustafsson JK, et al. The mucus and mucins of the goblet cells and enterocytes provide the first defense line of the gastrointestinal tract and interact with the immune system. Immunol Rev. 2014;260(1):8-20. doi:10.1111/ imr. 12182

14. De Weirdt R, Van de Wiele T. Micromanagement in the gut: microenvironmental factors govern colon mucosal biofilm structure and functionality. NPJ Biofilms Microbiomes. 2015;1:15026. doi:10.1038/npjbiofilms.2015.26

15. Li H, Limenitakis JP, Ganal SC, Macpherson AJ. Penetrability of the inner mucus layer: who is out there? EMBO Rep. 2015;16 (2):127-129. doi:10.15252/embr.201439943

16. Sicard J-F, Le Bihan G, Vogeleer P, Jacques M, Harel J. Interactions of intestinal bacteria with components of the intestinal mucus. Front Cell Infect Microbiol. 2017;1:7.

17. Johansson MEV, Phillipson M, Petersson J, Velcich A, Holm L, Hansson GC. The inner of the two Muc2 mucin-dependent mucus layers in colon is devoid of bacteria. Proc National Acad Sci. 2008;105(39):15064-15069. doi:10.1073/pnas.0803124105

18. van der Post S, Jabbar KS, Birchenough G, et al. Structural weakening of the colonic mucus barrier is an early event in ulcerative colitis pathogenesis. Gut. 2019;68(12):2142-2151. doi:10.1136/gutjnl-2018-317571

19. Da Silva S, Robbe-Masselot C, Ait-Belgnaoui A, et al. Stress disrupts intestinal mucus barrier in rats via mucin O-glycosylation shift: prevention by a probiotic treatment. Am $J$ Physiol Gastrointest Liver Physiol. 2014;307(4):G420-G429. doi:10.1152/ajpgi.00290.2013

20. Bergstrom K, Liu X, Zhao Y, et al. Defective intestinal mucin-type O-glycosylation causes spontaneous colitis-associated cancer in mice. Gastroenterology. 2016;151 (1):152-164.e11. doi:10.1053/j.gastro.2016.03.039

21. Larsson JMH, Karlsson $\mathrm{H}$, Crespo JG, et al. Altered O-glycosylation profile of MUC2 mucin occurs in active ulcerative colitis and is associated with increased inflammation. Inflamm Bowel Dis. 2011;17(11):2299-2307. doi:10.1002/ ibd. 21625

22. Timpte CS, Eckhardt AE, Abernethy JL, Hill RL. Porcine submaxillary gland apomucin contains tandemly repeated, identical sequences of 81 residues. $J$ Biol Chem. 1988;263(2):1081-1088. doi:10.1016/S0021-9258(19)35463-8

23. Gupta R, Jentoft N. Subunit structure of porcine submaxillary mucin. Biochemistry. 1989;28(14):6114-6121. doi:10.1021/ bi00440a 058

24. Corfield AP, Berry M. Glycan variation and evolution in the eukaryotes. Trends Biochem Sci. 2015;40(7):351-359. doi:10.1016/j.tibs.2015.04.004

25. Martens EC, Neumann M, Desai MS. Interactions of commensal and pathogenic microorganisms with the intestinal mucosal barrier. Nat Rev Microbiol. 2018;16(8):457-470. doi:10.1038/ s41579-018-0036-x

26. Bennett EP, Mandel U, Clausen H, Gerken TA, Fritz TA, Tabak LA. Control of mucin-type O-glycosylation: a classification of the polypeptide GalNAc-transferase gene family. Glycobiology. 2012;22(6):736-756. doi:10.1093/glycob/ cwr182

27. Schnaar RL. Glycobiology simplified: diverse roles of glycan recognition in inflammation. $J$ Leukoc Biol. 2016;99 (6):825-838. doi:10.1189/jlb.3RI0116-021R
28. Fu J, Wei B, Wen T, et al. Loss of intestinal core 1-derived O-glycans causes spontaneous colitis in mice. J Clin Invest. 2011;121(4):1657-1666. doi:10.1172/JCI45538

29. Moran AP, Gupta A, Joshi L. Sweet-talk: role of host glycosylation in bacterial pathogenesis of the gastrointestinal tract. Gut. 2011;60(10):1412-1425. doi:10.1136/gut.2010.212704

30. Johansson MEV, Thomsson KA, Hansson GC. Proteomic analyses of the two mucus layers of the colon barrier reveal that their main component, the Muc2 mucin, is strongly bound to the fcgbp protein. J Proteome Res. 2009;8(7):3549-3557. doi:10.1021/pr9002504

31. Jensen PH, Kolarich D, Packer NH. Mucin-type O-glycosylationputting the pieces together. FEBS J. 2010;277(1):81-94. doi:10.1111/j.1742-4658.2009.07429.x

32. Ju T, Brewer K, D'Souza A, Cummings RD, Canfield WM. Cloning and expression of human core 1 ß1,3-galactosyltransferase. J Biol Chem. 2002;277(1):178-186. doi:10.1074/jbc.M109060200

33. Fu J, Gerhardt H, McDaniel JM, et al. Endothelial cell O-glycan deficiency causes blood/lymphatic misconnections and consequent fatty liver disease in mice. $J$ Clin Invest. 2008;118 (11):3725-3737. doi:10.1172/JCI36077

34. Xia L, Ju T, Westmuckett A, et al. Defective angiogenesis and fatal embryonic hemorrhage in mice lacking core 1-derived O-glycans. J Cell Biol. 2004;164(3):451-459. doi:10.1083/ jcb.200311112

35. Bergstrom K, Fu J, Johansson MEV, et al. Core 1- and 3-derived O-glycans collectively maintain the colonic mucus barrier and protect against spontaneous colitis in mice. Mucosal Immunol. 2017;10(1):91-103. doi:10.1038/mi.2016.45

36. Bergstrom KSB, Xia L. Mucin-type O-glycans and their roles in intestinal homeostasis. Glycobiology. 2013;23(9):1026-1037. doi:10.1093/glycob/cwt045

37. An G, Wei B, Xia B, et al. Increased susceptibility to colitis and colorectal tumors in mice lacking core 3-derived O-glycans. $J$ Exp Med. 2007;204(6):1417-1429. doi:10.1084/jem.20061929

38. Thomsson KA, Holmén-Larsson JM, Angström J, Johansson ME, Xia L, Hansson GC. Detailed O-glycomics of the Muc2 mucin from colon of wild-type, core 1- and core 3-transferase-deficient mice highlights differences compared with human MUC2. Glycobiology. 2012;22(8):1128-1139. doi:10.1093/glycob/cws083

39. Reinoso Webb C, Koboziev I, Furr KL, Grisham MB. Protective and pro-inflammatory roles of intestinal bacteria. Pathophysiology. 2016;23(2):67-80. doi:10.1016/j.pathophys.2016.02.002

40. Rawls JF, Mahowald MA, Ley RE, Gordon JI. Reciprocal gut microbiota transplants from zebrafish and mice to germ-free recipients reveal host habitat selection. Cell. 2006;127(2):423-433. doi:10.1016/j.cell.2006.08.043

41. Bäckhed F, Ley RE, Sonnenburg JL, Peterson DA, Gordon JI. Host-bacterial mutualism in the human intestine. Science. 2005;307(5717):1915-1920. doi:10.1126/science.1104816

42. Spor A, Koren O, Ley R. Unravelling the effects of the environment and host genotype on the gut microbiome. Nat Rev Microbiol. 2011;9(4):279-290. doi:10.1038/nrmicro2540

43. Salzman NH, Ghosh D, Huttner KM, Paterson Y, Bevins CL. Protection against enteric salmonellosis in transgenic mice expressing a human intestinal defensin. Nature. 2003;422 (6931):522-526. doi:10.1038/nature01520

44. Bevins CL. Paneth cell defensins: key effector molecules of innate immunity. Biochem Soc Trans. 2006;34(Pt 2):263-266. doi:10.1042/BST0340263

45. Sommer F, Adam N, Johansson MEV, Xia L, Hansson GC, Bäckhed F. Altered mucus glycosylation in core 1 O-glycandeficient mice affects microbiota composition and intestinal architecture. PLoS One. 2014;9(1):e85254. doi:10.1371/journal. pone. 0085254 
46. Staubach F, Künzel S, Baines $\mathrm{AC}$, et al. Expression of the blood-group-related glycosyltransferase B4galnt2 influences the intestinal microbiota in mice. ISME J. 2012;6(7):1345-1355. doi:10.1038/ismej.2011.204

47. Kudelka MR, Hinrichs BH, Darby T, et al. Cosmc is an X-linked inflammatory bowel disease risk gene that spatially regulates gut microbiota and contributes to sex-specific risk. Proc Natl Acad Sci U S A. 2016;113(51):14787-14792. doi:10.1073/pnas.1612158114

48. Rausch P, Rehman A, Künzel S, et al. Colonic mucosa-associated microbiota is influenced by an interaction of Crohn disease and FUT2 (Secretor) genotype. Proc Natl Acad Sci U S A. 2011;108 (47):19030-19035. doi:10.1073/pnas.1106408108

49. Nakayama J, Yeh JC, Misra AK, Ito S, Katsuyama T, Fukuda M. Expression cloning of a human alpha1, 4-N-acetylglucos aminyltransferase that forms GlcNAcalpha1 $->4$ Galbeta $->R$, a glycan specifically expressed in the gastric gland mucous celltype mucin. Proc Natl Acad Sci U S A. 1999;96(16):8991-8996. doi:10.1073/pnas.96.16.8991

50. Karasawa F, Shiota A, Goso Y, et al. Essential role of gastric gland mucin in preventing gastric cancer in mice. J Clin Invest. 2012;122(3):923-934. doi:10.1172/JCI59087

51. Etienne-Mesmin L, Chassaing B, Desvaux M, et al. Experimental models to study intestinal microbes-mucus interactions in health and disease. FEMS Microbiol Rev. 2019;43(5):457-489.

52. Bergstrom K, Shan X, Casero D, et al. Proximal colon-derived O-glycosylated mucus encapsulates and modulates the microbiota. Science. 2020;370(6515):467-472.

53. Liu F, Fu J, Bergstrom K, et al. Core 1-derived mucin-type $\mathrm{O}$-glycosylation protects against spontaneous gastritis and gastric cancer. $J$ Exp Med. 2020;217:1. doi:10.1084/jem.20182325

54. Van Klinken BJ, Dekker J, Büller HA, Einerhand AW. Mucin gene structure and expression: protection vs. adhesion. $A m$ J Physiol. 1995;269(5 Pt 1):G613-G627.

55. Martín-Sosa S, Martín M-J, Hueso P. The sialylated fraction of milk oligosaccharides is partially responsible for binding to enterotoxigenic and uropathogenic Escherichia coli human strains. J Nutr. 2002;132(10):3067-3072. doi:10.1093/jn/131.10.3067

56. Ruiz-Palacios GM, Cervantes LE, Ramos $\mathrm{P}$, Chavez-Munguia B, Newburg DS. Campylobacter jejuni binds intestinal $\mathrm{H}(\mathrm{O})$ antigen (Fuc alpha 1, 2Gal beta 1, 4GlcNAc), and fucosyloligosaccharides of human milk inhibit its binding and infection. $J$ Biol Chem. 2003;278(16):14112-14120. doi:10.1074/jbc.M207744200

57. Mahdavi J, Pirinccioglu N, Oldfield NJ, et al. A novel O-linked glycan modulates Campylobacter jejuni major outer membrane protein-mediated adhesion to human histo-blood group antigens and chicken colonization. Open Biol. 2014;4:130202. doi:10.1098/ rsob. 130202

58. Poole J, Day CJ, von Itzstein M, Paton JC, Jennings MP. Glycointeractions in bacterial pathogenesis. Nat Rev Microbiol. 2018;16(7):440-452. doi:10.1038/s41579-018-0007-2

59. Erdem AL, Avelino F, Xicohtencatl-Cortes J, Girón JA. Host protein binding and adhesive properties of $\mathrm{H} 6$ and $\mathrm{H} 7$ flagella of attaching and effacing Escherichia coli. J Bacteriol. 2007;189 (20):7426-7435. doi:10.1128/JB.00464-07

60. Ramamurthy T, Nandy RK, Mukhopadhyay AK, et al. Virulence regulation and innate host response in the pathogenicity of Vibrio cholerae. Front Cell Infect Microbiol. 2020;10:572096. doi:10.3389/fcimb.2020.572096

61. Guzman-Aranguez A, Argüeso P. Structure and biological roles of mucin-type O-glycans at the ocular surface. Ocul Surf. 2010;8 (1):8-17. doi:10.1016/S1542-0124(12)70213-6

62. Sumiyoshi M, Ricciuto J, Tisdale A, Gipson IK, Mantelli F, Argüeso P. Antiadhesive character of mucin O-glycans at the apical surface of corneal epithelial cells. Invest Ophthalmol Vis Sci. 2008;49(1):197-203. doi:10.1167/iovs.07-1038
63. Xia B, Royall JA, Damera G, Sachdev GP, Cummings RD Altered O-glycosylation and sulfation of airway mucins associated with cystic fibrosis. Glycobiology. 2005;15(8):747-775. doi:10.1093/glycob/cwi061

64. Vogt SL, Peña-Díaz J, Finlay BB. Chemical communication in the gut: effects of microbiota-generated metabolites on gastrointestinal bacterial pathogens. Anaerobe. 2015;34:106-115. doi:10.1016/j. anaerobe.2015.05.002

65. Wheeler KM, Cárcamo-Oyarce G, Turner BS, et al. Mucin glycans attenuate the virulence of Pseudomonas aeruginosa in infection. Nat Microbiol. 2019;4(12):2146-2154. doi:10.1038/s41564-019-0581-8

66. Alemka A, Clyne M, Shanahan F, Tompkins T, Corcionivoschi N, Bourke B. Probiotic colonization of the adherent mucus layer of HT29MTXE12 cells attenuates Campylobacter jejuni virulence properties. Infect Immun. 2010;78(6):2812-2822. doi:10.1128/ IAI.01249-09

67. Wang BX, Wheeler KM, Cady KC, et al. Mucin glycans signal through the sensor kinase rets to inhibit virulence-associated traits in Pseudomonas aeruginosa. Curr Biol. 2021;31(1):90-102.e7. doi:10.1016/j.cub.2020.09.088

68. Koropatkin NM, Cameron EA, Martens EC. How glycan metabolism shapes the human gut microbiota. Nat Rev Microbiol. 2012;10(5):323-335. doi:10.1038/nrmicro2746

69. Yamada T, Hino S, Iijima $\mathrm{H}$, et al. Mucin O-glycans facilitate symbiosynthesis to maintain gut immune homeostasis. EBioMedicine. 2019;48:513-525. doi:10.1016/j.ebiom.2019.09.008

70. Derrien M, Vaughan EE, Plugge CM, de Vos WM. Akkermansia muciniphila gen. nov., sp. nov., a human intestinal mucin-degrading bacterium. Int $J$ Syst Evol Microbiol. 2004;54 (Pt 5):1469-1476. doi:10.1099/ijs.0.02873-0

71. Ottman N, Geerlings SY, Aalvink S, de Vos WM, Belzer C. Action and function of Akkermansia muciniphila in microbiome ecology, health and disease. Best Pract Res Clin Gastroenterol. 2017;31(6):637-642. doi:10.1016/j.bpg.2017.10.001

72. Sonnenburg JL, Xu J, Leip DD, et al. Glycan foraging in vivo by an intestine-adapted bacterial symbiont. Science. 2005;307 (5717):1955-1959. doi:10.1126/science.1109051

73. Wrzosek L, Miquel S, Noordine M-L, et al. Bacteroides thetaiotaomicron and Faecalibacterium prausnitzii influence the production of mucus glycans and the development of goblet cells in the colonic epithelium of a gnotobiotic model rodent. BMC Biol. 2013;11:61. doi:10.1186/1741-7007-11-61

74. Png CW, Lindén SK, Gilshenan KS, et al. Mucolytic bacteria with increased prevalence in IBD mucosa augment in vitro utilization of mucin by other bacteria. Am J Gastroenterol. 2010;105 (11):2420-2428. doi:10.1038/ajg.2010.281

75. Katoh T, Ojima MN, Sakanaka M, Ashida H, Gotoh A, Katayama T. Enzymatic adaptation of to host glycans, viewed from glycoside hydrolyases and carbohydrate-binding modules. Microorganisms. 2020;8(4):481. doi:10.3390/microorganisms8040481

76. Turroni F, Bottacini F, Foroni E, et al. Genome analysis of Bifidobacterium bifidum PRL2010 reveals metabolic pathways for host-derived glycan foraging. Proc Natl Acad Sci U S A. 2010;107(45):19514-19519. doi:10.1073/pnas.1011100107

77. Garrido D, Kim JH, German JB, Raybould HE, Mills DA. Oligosaccharide binding proteins from Bifidobacterium longum subsp. infantis reveal a preference for host glycans. PLoS One. 2011;6(3):e17315. doi:10.1371/journal.pone.0017315

78. Marcobal A, Barboza M, Sonnenburg ED, et al. Bacteroides in the infant gut consume milk oligosaccharides via mucus-utilization pathways. Cell Host Microbe. 2011;10 (5):507-514. doi:10.1016/j.chom.2011.10.007

79. Luijkx YMCA, Bleumink NMC, Jiang J, et al. Bacteroides fragilis fucosidases facilitate growth and invasion of Campylobacter jejuni in the presence of mucins. Cell Microbiol. 2020;22(12): e13252. doi:10.1111/cmi.13252 
80. Crost EH, Tailford LE, Le Gall G, Fons M, Henrissat B, Juge N. Utilisation of mucin glycans by the human gut symbiont Ruminococcus gnavus is strain-dependent. PLoS One. 2013;8 (10):e76341. doi:10.1371/journal.pone.0076341

81. Coyne MJ, Reinap B, Lee MM, Comstock LE. Human symbionts use a host-like pathway for surface fucosylation. Science. 2005;307(5716):1778-1781. doi:10.1126/science.1106469

82. Ryan FJ, Ahern AM, Fitzgerald RS, et al. Colonic microbiota is associated with inflammation and host epigenomic alterations in inflammatory bowel disease. Nat Commun. 2020;11(1):1512. doi:10.1038/s41467-020-15342-5

83. Garrett WS. The gut microbiota and colon cancer. Science. 2019;364(6446):1133-1135. doi:10.1126/science.aaw2367

84. Hino S, Mizushima T, Kaneko K, et al. Mucin-derived O-glycans act as endogenous fiber and sustain mucosal immune homeostasis via short-chain fatty acid production in rat cecum. $J$ Nutr. 2020;150(10):2656-2665. doi:10.1093/jn/nxaa097

85. Levy GN, Aminoff D. Purification and properties of alpha-N-acetylgalactosaminidase from Clostridium perfringens. J Biol Chem. 1980;255(24):11737-11742. doi:10.1016/S00219258(19)70196-3

86. Prizont R. Degradation of intestinal glycoproteins by pathogenic Shigella flexneri. Infect Immun. 1982;36(2):615-620. doi:10.1128/iai.36.2.615-620.1982

87. Matos R, Fonseca KL, Mereiter S, et al. Infection up-regulates sialyl Lewis $\mathrm{X}$ expression in the lung epithelium. Microorganisms. 2021;9(1):99. doi:10.3390/microorganisms 9010099

88. Sharma R, Schumacher U, Ronaasen V, Coates M. Rat intestinal mucosal responses to a microbial flora and different diets. Gut. 1995;36(2):209-214. doi:10.1136/gut.36.2.209

89. Burger-van Paassen N, Vincent A, Puiman PJ, et al. The regulation of intestinal mucin MUC2 expression by short-chain fatty acids: implications for epithelial protection. Biochem J. 2009;420 (2):211-219. doi:10.1042/BJ20082222

90. Gaudier E, Jarry A, Blottière HM, et al. Butyrate specifically modulates MUC gene expression in intestinal epithelial goblet cells deprived of glucose. Am J Physiol Gastrointest Liver Physiol. 2004;287(6):G1168-G1174. doi:10.1152/ajpgi.00219.2004

91. Hatayama H, Iwashita J, Kuwajima A, Abe T. The short chain fatty acid, butyrate, stimulates MUC2 mucin production in the human colon cancer cell line, LS174T. Biochem Biophys Res Commun. 2007;356(3):599-603. doi:10.1016/j.bbrc.2007.03.025

92. Cooke CL, An HJ, Kim J, et al. Modification of gastric mucin oligosaccharide expression in rhesus macaques after infection with Helicobacter pylori. Gastroenterology. 2009;137(3):10611071.e8. doi:10.1053/j.gastro.2009.04.014

93. Venkatakrishnan V, Quintana-Hayashi MP, Mahu M, Haesebrouck F, Pasmans F, Lindén SK. Brachyspira hyodysenteriae infection regulates mucin glycosylation synthesis inducing an increased expression of Core-2 O-glycans in porcine colon. J Proteome Res. 2017;16 (4):1728-1742. doi:10.1021/acs.jproteome.7b00002

94. Macia L, Thorburn AN, Binge LC, et al. Microbial influences on epithelial integrity and immune function as a basis for inflammatory diseases. Immunol Rev. 2012;245(1):164-176. doi:10.1111/ j.1600-065X.2011.01080.x

95. Perez-Lopez A, Behnsen J, Nuccio S-P, Raffatellu M. Mucosal immunity to pathogenic intestinal bacteria. Nat Rev Immunol. 2016;16(3):135-148. doi:10.1038/nri.2015.17

96. Kurashima Y, Kiyono H. Mucosal ecological network of epithelium and immune cells for gut homeostasis and tissue healing. Annu Rev Immunol. 2017;35:119-147. doi:10.1146/annurevimmunol-051116-052424

97. Shan M, Gentile M, Yeiser JR, et al. Mucus enhances gut homeostasis and oral tolerance by delivering immunoregulatory signals. Science. 2013;342(6157):447-453. doi:10.1126/science.1237910
98. Okumura R, Takeda K. Roles of intestinal epithelial cells in the maintenance of gut homeostasis. Exp Mol Med. 2017;49(5):e338. doi:10.1038/emm.2017.20

99. de Visser KE, Eichten A, Coussens LM. Paradoxical roles of the immune system during cancer development. Nat Rev Cancer. 2006;6(1):24-37. doi:10.1038/nrc1782

100. Kudelka MR, Stowell SR, Cummings RD, Neish AS. Intestinal epithelial glycosylation in homeostasis and gut microbiota interactions in IBD. Nat Rev Gastroenterol Hepatol. 2020;17(10):597-617.

101. Cascio S, Faylo JL, Sciurba JC, et al. Abnormally glycosylated MUC1 establishes a positive feedback circuit of inflammatory cytokines, mediated by NF- $\mathrm{kB}$ p65 and EzH2, in colitisassociated cancer. Oncotarget. 2017;8(62):105284-105298. doi:10.18632/oncotarget.22168

102. Carrascal MA, Severino PF, Guadalupe Cabral M, et al. Sialyl Tn-expressing bladder cancer cells induce a tolerogenic phenotype in innate and adaptive immune cells. Mol Oncol. 2014;8 (3):753-765. doi:10.1016/j.molonc.2014.02.008

103. Ogata S, Maimonis PJ, Itzkowitz SH. Mucins bearing the cancer-associated sialosyl-Tn antigen mediate inhibition of natural killer cell cytotoxicity. Cancer Res. 1992;52(17):4741-4746.

104. Videira PA, Amado IF, Crespo HJ, et al. Surface alpha 2-3- and alpha 2-6-sialylation of human monocytes and derived dendritic cells and its influence on endocytosis. Glycoconj J. 2008;25 (3):259-268. doi:10.1007/s10719-007-9092-6

105. Lu P, Burger-van Paassen N, van der Sluis M, et al. Colonic gene expression patterns of mucin Muc2 knockout mice reveal various phases in colitis development. Inflamm Bowel Dis. 2011;17 (10):2047-2057. doi:10.1002/ibd.21592

106. Han X, Ding S, Jiang H, Liu G. Roles of macrophages in the development and treatment of gut inflammation. Front Cell Dev Biol. 2021;9:625423. doi:10.3389/fcell.2021.625423

107. Kvorjak M, Ahmed Y, Miller ML, et al. Cross-talk between colon cells and macrophages increases ST6GALNAC1 and MUC1-sTn expression in ulcerative colitis and colitis-associated colon cancer. Cancer Immunol Res. 2020;8(2):167-178. doi:10.1158/ 2326-6066.CIR-19-0514

108. Wakui H, Fuseya S, Suzuki R, et al. Incomplete clearance of apoptotic cells by core 1-derived O-glycan-deficient resident peritoneal macrophages. Biochem Biophys Res Commun. 2018;495 (2):2017-2023. doi:10.1016/j.bbrc.2017.12.066

109. Gurram RK, Zhu J. Orchestration between ILC2s and Th2 cells in shaping type 2 immune responses. Cell Mol Immunol. 2019;16 (3):225-235. doi:10.1038/s41423-019-0210-8

110. McDermott JR, Humphreys NE, Forman SP, Donaldson DD, Grencis RK. Intraepithelial NK cell-derived IL-13 induces intestinal pathology associated with nematode infection. $J$ Immunol. 2005;175(5):3207-3213. doi:10.4049/jimmunol.175.5.3207

111. Smids C, Horjus Talabur Horje CS, Drylewicz J, et al. Intestinal $\mathrm{T}$ cell profiling in inflammatory bowel disease: linking $\mathrm{T}$ cell subsets to disease activity and disease course. J Crohns Colitis. 2018;12(4):465-475. doi:10.1093/ecco-jcc/jjx160

112. Xavier RJ, Podolsky DK. Unravelling the pathogenesis of inflammatory bowel disease. Nature. 2007;448(7152):427-434. doi:10.1038/nature06005

113. Kaser A, Zeissig S, Blumberg RS. Inflammatory bowel disease. Annu Rev Immunol. 2010;28:573-621. doi:10.1146/annurevimmunol-030409-101225

114. Nishida A, Nagahama $K$, Imaeda $H$, et al. Inducible colitis-associated glycome capable of stimulating the proliferation of memory CD4+ T cells. J Exp Med. 2012;209(13):2383-2394. doi:10.1084/jem.20112631

115. Ohnmacht C, Park J-H, Cording S, et al. MUCOSAL IMMUNOLOGY. The microbiota regulates type 2 immunity through ROR $\gamma \mathrm{t}^{+}$T cells. Science. 2015;349(6251):989-993. doi:10.1126/science.aac4263 
116. Sefik E, Geva-Zatorsky N, Oh S, et al. MUCOSAL IMMUNOLOGY. Individual intestinal symbionts induce a distinct population of $\operatorname{ROR} \gamma^{2}$ regulatory $\mathrm{T}$ cells. Science. 2015;349(6251):993-997. doi:10.1126/science.aaa9420

117. Jacobs JP, Lin L, Goudarzi M, et al. Microbial, metabolomic, and immunologic dynamics in a relapsing genetic mouse model of colitis induced by T-synthase deficiency. Gut Microbes. 2017;8 (1):1-16. doi:10.1080/19490976.2016.1257469
118. Brown SJ, Miller AM, Cowan PJ, et al. Altered immune system glycosylation causes colitis in alpha1,2-fucosyltransferase transgenic mice. Inflamm Bowel Dis. 2004;10(5):546-556. doi:10.1097/00054725-200409000-00008

\section{Publish your work in this journal}

The Journal of Inflammation Research is an international, peerreviewed open-access journal that welcomes laboratory and clinical findings on the molecular basis, cell biology and pharmacology of inflammation including original research, reviews, symposium reports, hypothesis formation and commentaries on: acute/chronic inflammation; mediators of inflammation; cellular processes; molecular mechanisms; pharmacology and novel anti-inflammatory drugs; clinical conditions involving inflammation. The manuscript management system is completely online and includes a very quick and fair peerreview system. Visit http://www.dovepress.com/testimonials.php to read real quotes from published authors.

Submit your manuscript here: https://www.dovepress.com/journal-of-inflammation-research-journal 